\title{
Sand Seismic Liquefaction Landslide-slipping and Debris and Treatment
}

\author{
Wen-Hua $\mathrm{CHEN}^{1, \mathrm{a}}$, Qian ZHANG ${ }^{2, \mathrm{~b}}$, Qi SONG ${ }^{3, \mathrm{c}}$ \\ ${ }^{1,2,3}$ Civil Engineering Department, Beijing Jiaotong University, Beijing China, 100044

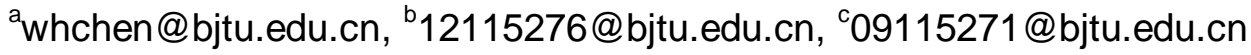

Keywords: Earthquake Liquefaction, Slip and Debris, Evaluation and Defend the Disasters.

\begin{abstract}
Some kinds of slope slipping induced by seismic liquefaction are researched and listed by summarized the earthquake -disasters ,the status and conditions of liquefied soil layer including faults, the level of underground water ,buried-depth, the angle ,thickness and scope of liquefied soil layer are studied to evaluate the liquefaction and think of the effect from conditions of surface-ground and landform, and to analysis the movement and deform of soil layer and surface of stratum, the result of slip and debris by liquefaction are forecasted, the law and formulation of slipping-mass are set up ,it is described into three parts: flow, slip and movement of mass. some method and progress are suggested to reduce the affairs of slip and debris.
\end{abstract}

\section{Introduction}

In 2001, A 7.6 magnitude earthquake induced a huge debris flow in Salvador, the debris flow had crossed More than a quarter mile, and hundreds of families were buried. In Taiwan ' 9.21 ' earthquake, some mountain soil liquefaction first and landslip then. In 1920, the 8.5 magnitude Haiyuan earthquake in Ningxia, made the Malan loess from the quaternary loess platform of Qingshui River which in Shibeiyuan northwest of Guyuan low angle slip with a wide range along its sand layer, saturated sand layer buried depth is $11 \mathrm{~m}$ to $20 \mathrm{~m}$, slip mass $16 \mathrm{Km}$ long, $1.2-1.8 \mathrm{Km}$ wide along the strike. In Tangshan earthquake, bank slip, crack, and sandblast from DouHe, luanhe river, JiYunHe, Old way of the haihe river, YueYaHe made more than 10 highway and railway bridges shorten in length, abutment tilted, piers broke, beam fells off, channel narrowed, such as Tangshan victory bridge, Yuehe bridge, Hangu bridge etc, there was slip on both sides of the YueYaHe. After 7.8 magnitude Luzon earthquake in Philippine in1990, liquefaction made the riverbank of Pantal river displaced about $10 \mathrm{~m}$ to the channel center, a pavement also displaced about $1 \mathrm{~m}$ to the channel center, two buildings displaced north about $3 \mathrm{~m}$ and $1 \mathrm{~m}$, a large number of underground pipeline and well be destroyed. This paper mainly focuses on engineering prevention management of slip caused by liquefaction.

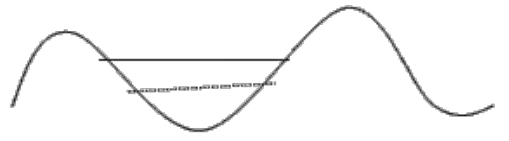

Fig. 1 Level-Layer Lied on Un-Level Rock Base

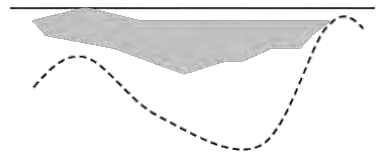

Fig. 3 Thickness is Big and Change, Surface is Level, Rock Base is Change

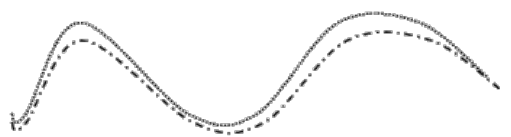

Fig. 2 Sand Layer Change with Landform

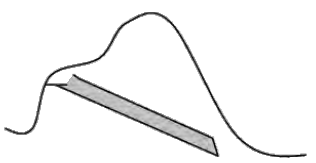

Fig. 4 Sand Layer is Slang Landform is Complex

\section{The Influence of Terrain Conditions on Sand Layer Liquefaction}

The soil dynamic response during earthquake is obviously different in level-layer and complex terrain with tilt and bump, so the liquefaction possibility of level-layer and complex terrain will be different, and the result of liquefaction will also be different. Earthquake is the dynamic response of a large area, it is not 
a dynamic problem of a specific site, also not a One dimensional wave problem, but the site is small, so whether domestic or abroad, the site will not be considered into the whole environment of the terrain or level-layer when discriminate its liquefaction. The existing liquefaction discrimination standard only suitable for the site without buildings, more did not consider the influence of terrain conditions. The site will not be connected with the terrain around when discriminate its liquefaction. When level-layer is used to discriminate the liquefaction of inclined formation, scattering effect of terrain conditions to the wave will not been considered, because of this scattering effect, the liquefaction discrimination of sand layer in complex terrain will not been that simple by the recommended empirical method from the standard. Specific terrain may aggravate the liquefaction in sand layer and the harmfulness of liquefaction, terrain conditions will change the soil dynamic response, stress field will been more different in complex terrain or level-layer, and liquefied situation and conditions will also change considerably, mainly displays in the following respects: ( I ) Possibility and degree of liquefaction will change, liquefaction will happen actually in some level-layer site where had been thought will not will liquefy. (II) Terrain conditions outstanding performance on the difference intensity of liquefaction and earthquake damage (III) Terrain conditions control the surface damage form induced by the liquefaction, such as landslide and debris flow. Terrain conditions mainly in the followings: alluvial plains, hills area, landslides, bedrock for bump shape, surface for relief form, the surface is flat shape but bedrock is relief form, etc.. Only the accurate judgment for liquefaction of saturated sand or powder soil in complex terrain can help to prevent and control the possible liquefaction hazard layer, the main factors of investigation is: occurrence (buried depth, inclination, thickness, etc.), terrain conditions, etc. the consideration with the possibility of the slip large liquefied layer is not too reasonable, respectively reference figure 1 - figure 4 . In figure 1 slip caused by liquefaction is not obvious, but liquefaction is influenced by bedrock. In figure 1 layer slip is very serious, the liquefaction degree is very different, the definition of liquefied soil depth will become difficult but some has to be answered. In figure 1 - figure 5 the liquefaction discrimination are according to method for free level-layer site, obviously this will produce many error. In short, site liquefaction discrimination should be linked up with terrain conditions, commonly laboratory model tests and numerical analysis method are used to solve these problems at present.

\section{Landslide and Debris Flow Induced by Liquefaction}

Through the material investigation and analysis of seismic damage, it can be concluded the following points:

(1)The mainly soil types which cause liquefaction landslide, mudflow and mudslides are sand, silt, clay, gravel soil and so on. (2)Terrain conditions directly affect the occurrence and development of liquefaction landslide, liquefaction in absolute level-site will not happen layer flow, inclined layer and slope body, landslides, layer with rolling rock will happen liquefaction or overlying layer flow easily, Terrain conditions directly affect movement rules and severe degree of liquefaction flow. In 1964, the maximum slip distance was $1000 \mathrm{~m}$ in Alaska, the maximum slip area was 4,800,000 square feet, and surface damage was very seriously. (3)Seismic energy directly affect the possibility and severe degree of liquefaction landslide, scour and vertical flow slide is the most severe flow slide form, such as high-speed landslide of high steep slope body caused by soil liquefaction in strong earthquake, In 2001, San Salvador had 1200 casualties. (4)Most of the liquefaction landslide occurred in the earthquake, and the time is short, but liquefaction flow slide events often existed after the earthquake and caused great casualties. In 1920's Gansu earthquake, large ground movement has led to 200,000 casualties, compared with the landslide and debris flow caused by flash floods, heavy rains, debris flow caused by liquefaction is more sudden, hardly poor forecasting and more damaging.

\section{Several Typical Liquefaction Landslide Forms}

There are many influence factors of landslide and debris flow, forms of the landslide and debris flow caused by earthquake liquefaction are so many too, here are some types.

\section{Sliding Caused by Thin Sand Layer Liquefaction}

In this kind of situation, liquefied soil is sliding control layer, the overlying soil slide along the liquefaction layer. If loose saturated silt and sand occurs in the soil or rock hard, and overlying a layer of 
hard soil with certain thickness, but not too big, it will occur in layer or thin layer forms, when sand layer or rock slope, soil liquefaction caused by seismic waves can make the overlying soil slope (as a rigid body) along the bottom of the liquefied layer for lateral sliding. At this time, the soil after the sliding body will sink in the space formed by moving forward of soil, and then the graben will be formed. When this form of movement occurs, buildings on main sliding body will happen a lot of uneven subsidence and often cause to full damage, at the same time sliding process of sliding body will fully destroy the surface and its structure of the downstream or along the sliding process. Tonghai earthquake in Yunnan (1970), YuGuHe happened liquefaction slip, the farmhouse originally built on the stable buttress stone layer, due to the lower sand layer has first liquefied, and then transferred to buttress stone layer, which happened nearly $200 \mathrm{~m}$ level slip.

\section{Slip Problems}

In this kind of situation, liquefied soil layer is the main body of the movement. If liquefaction happen in the inclined soil body or the lower part of it, the soil will flow or move to the side without support, this kind of phenomenon is called flow slide. Flow slide of seismic liquefaction is one of the most serious earthquake disasters, most of the liquid flow slide events happened in the side slope, bank slope, roadbed, inclined strata, plateau, mountainous and hilly areas, seismic flow slip damage material in the absolute level site of the flow is very little, mountainous and hilly areas, plateau and tilted terrain are indispensable conditions for sliding. Reference figure 5, the Angle of the bedrock and the liquefied layers, the occurrence of substratum sliding control plane directly influence the generation and strata movement of liquid flow slide. A survey of liquefied soil thickness (maximum depth of flow slide), astratigraphic dip where liquid flow slide happen, and required minimum Angle formation for liquefied flow slide, can be for reference to later discrimination of liquefied ground which won't happen liquid flow slide, the rich deposit condition of sand body and soil which may be liquefied also influence the different flow slide form, such as sand liquefaction of incline layer can lead to formation flow, as well as soil layer which along with the slope, and under the underground water level line, will led to landslide if liquefied, the same slope, if the liquefied soil is not bedded deposit, but exist as lens or henroost shape, it will very easy to cause mudslides, Reference figure 11. From the earthquake damage material can be seen that the form of flow slide is multiple: inclined layer flow lowly, severe erosion of high, steep mountain and slope, regional intermittent movement characteristics of the hilly region in fluctuation. In Haiyuan earthquake in Ningxia, the maximum slip distance was 400m, the maximum slip area was 290,000 square feet

\section{Earthquake Liquefaction Occurred in Cracks of Fault}

If there is the weak surface which is old fault in the slope, and fault gouge filling in the fault have certain thickness, also some saturated sand in fault, or there is some liquefied material composition in the fault gouge, all these will liquefy because of violent movement of fault. As shown in figure, when earthquake, both flanks of fault will surely move constantly follow with shear wave, saturated sand layer in fault gouge will be liquefaction easily with the dual function of seismic load and fault movement, once liquefied, strength of cracks of fault will reduce quickly, the fault will slide if it is not level fault. Some landslide in Kobe earthquake in 1995 is just this situation

\section{Discrimination of Liquefaction and Analysis of Liquefied Harmfulness}

The sliding scale of landslide is mainly depend on sliding body and sliding terrain conditions. For different burial conditions of the sand layer and different occurrence, the possibility of liquefaction is different; the stability of the liquefied slope is different, the destruction forms of slope induced by liquefaction are also different, so founding the occurrence conditions of the sand layer and the relative slope is helpful to the analysis of the problem. For simple analysis, first hypothesis the following models: (1) The soil is located above underground water level; (2) sandy layer partly in groundwater, reference figure 9; (3) The soil completely under the underground water level; (4) the burial depth of liquefiable soil is less than $20 \mathrm{~m}$, the relative position of the slope and the long axis direction of sandy soil layer is as follows: the direction of the slope, the slope direction and vertical, reference figure $5,6.7 ;(5)$ the burial depth of liquefiable soil is too deep than $20 \mathrm{~m}$, reference figure 8 , liquefaction may cause the ground settlement, but not induced landslides; (6) liquefiable soil layer is stratified, and it is continuous; its 
attitude also change little; (7) the soil layer is not continuous, and the attitude is also complex, reference figure 10 , debris flow is easy to form in this case.

First liquefaction potential should be estimated, liquefaction cannot be considered in (1), (2), and (5); compared with the level ground, the liquefaction resistant level should be improved accordingly in (3), (4) , (6), and (7), so specific situation needs to be specialized.

Liquefaction hazard is follow-up work of the liquefaction discrimination, as liquefiable soil under the underground water, shallow buried, the slope will slide easily caused by the liquefaction along the direction of the slope sand, this case should be pay attention to. Which situation is the most safety, and which one is the most unfavorable should be discriminated. The pore pressure of the soil layer with part of which is unsaturated will spread to unsaturated soil under the action of seismic load, this will lead to excess pore water pressure, water is also likely transfer to dry soil, the possibility of liquefaction will be small. In case of figure 5 and the underground water level is above the possible sliding surface, control surface will along the long axis direction of the liquefiable soil layer.

\section{Multiple Sliding Hypothesis and Equation of Motion for Sliding Mass}

The soil is cellular, and relief, head of it is much bigger; this will lead to multiple sliding, and then may cause mudslides, reference figure 12. If there is some bigger sand-layered soil in the soil, there will form a weak surface; the soil will landslide if the sand-layered soil liquefied; multiple sliding and liquefaction will alternately happen in peaks and mountains, and then lead to large-scale debris flow ultimately. Although the landslide and debris flow has essential difference, but the disaster forming process should not have strict difference. Mostly if the first slope did not slide, the second slope will not liquefy or liquefy little, the second sliding slope will also load to the next slope, and lead the low-lying sand layer of the slope to liquefaction induced by the larger shear force; if the underground water level is higher, the fluidity of the liquefied layer is better, the distance of the fluid movement is farther, often lasted for several kilometers, the damage is severe and the scope of it is very large. The sequence of liquefaction and sliding is relative to the soil compactness and shear stress, of course, without the influence of the terrain. The model hypothesis of multiple liquefaction and multiple sliding can explain the reason why flow still exist after earthquake, of course, for shear load, liquefaction and shear failure can happen first, or this two exist at the same time, but the theory of the bigger shear load will lead to liquefaction is feasible.

Equation of motion for sliding mass: sliding surface is supposed as a determined, single rigid plane (can be plane, also can be surface), movement of sliding mass can be decomposed into sliding and flow: movement of sliding mass $=$ motion trail of fluid + glide path of sliding body along the slip plane.

$\mathrm{G}(\mathrm{x}, \mathrm{y}, \mathrm{z}, \mathrm{t})$ is boundary conditions or called terrain surface function, it can be simplified got by the engineering and surveying measurement. The following is the simplified analysis of the sliding surface is flat, and the sliding body can be treated as plane problem.

$$
\begin{aligned}
& F(x, y, z, t)=F_{1}(x, y, z, t)+F_{2}(x, y, z, t) \\
& G(x, y, z, t)=F_{3}(x, y, z, t)
\end{aligned}
$$

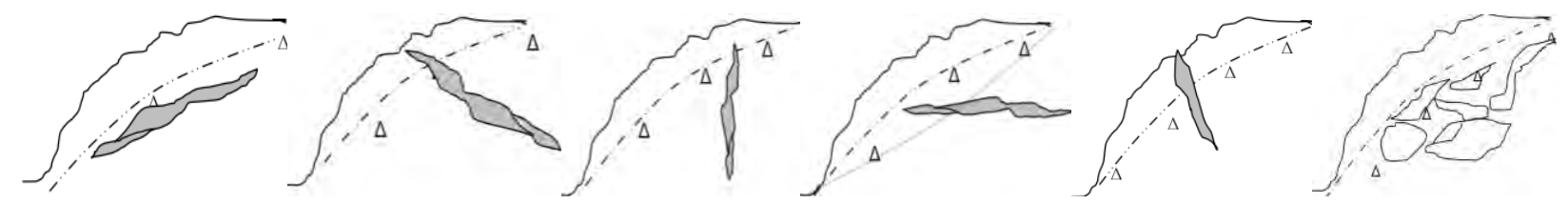

Fig. 5- Fig. 10 From up to down, from left to right, respectively are: (5)The Land Layer is Agree with the Slope; (6)The Long Axe of Sand Layer is against the Slope; (7)The Sand Layer is Upright; (8)Sand Layer is under the Slip-Plane; (9)Part of Sand Layer is above the Level-Groundwater; (10)A Case of Debris

(1) Flow analysis: take the contact point of the choose sliding body and sliding surface as origin of the local coordinate system, the sliding direction is $\mathrm{X}$, as shown in figure 13; if flow path is approximate elliptic, the trajectory of arbitrary point of the flow body is: 


$$
\frac{X^{2}}{a^{2}}+\frac{Y^{2}}{b^{2}}=1
$$

(2) Sliding analysis: sliding body is regarded as rigid body

The equation of motion for the decline:

$$
x=2(g \sin \alpha)^{2} t \cos \alpha ; y=2(g \sin \alpha)^{2} t \cos \alpha
$$

Coordinate transformation:

$$
Y=y \sin \alpha ; X=x \cos \alpha
$$

The general equation of motion can be written as:

$$
\begin{aligned}
& F(x, y, \alpha, t)=\left(\frac{x}{2 g \sin \alpha}\right)^{2}+\left(\frac{y}{2 g \cos \alpha}\right)^{2}-t^{2}+\left(\frac{x \cos \alpha}{a}\right)^{2}+\left(\frac{y \sin \alpha}{b}\right)^{2}-1=0 \\
& G(x, y, \alpha, t)=F_{3}(x, y, \alpha, t)
\end{aligned}
$$

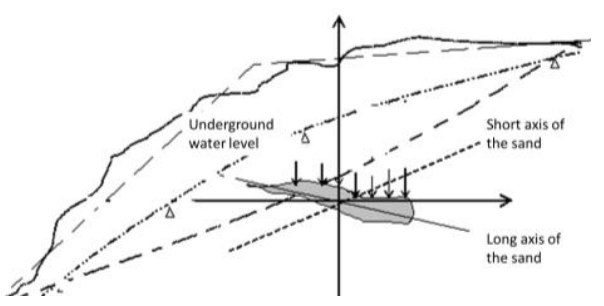

Fig. 11 The Relation of Long Axe of Sand with Underground Water or Slip-Plane

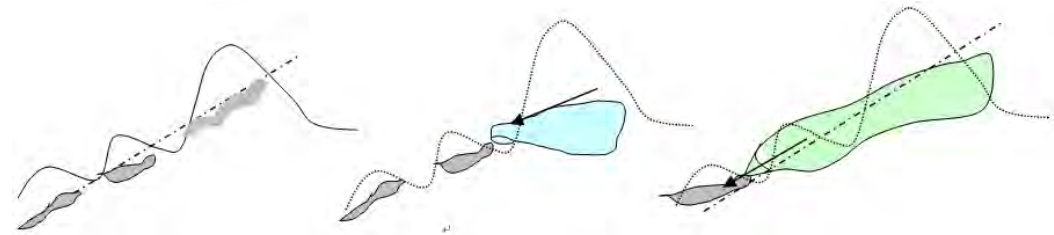

Fig. 12 Model of Move and Slip

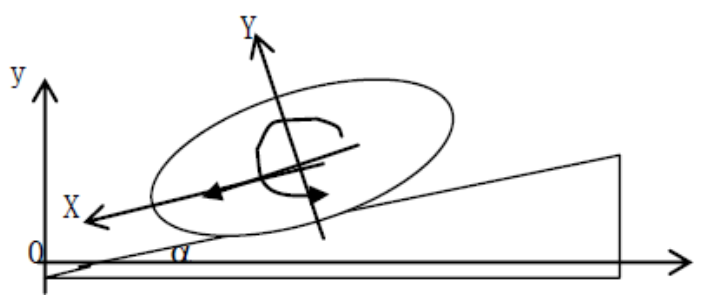

Fig. 13 Model of Slip and Flow of Liquefied Sand Layer

If use engineering method can get possible mathematics form of sliding surface or the topographic function, then the control boundary of sliding body will be got.

\section{Prevention and Management to Geotechnical Disasters of Landslide and Debris Flow Induced by Liquefaction}

According to the influence on the liquefied landslide by the occurrence of liquefied soil, buried depth, underground water and other conditions, engineering hazards induced by liquefaction in projects should be predicted. To prevent the occurrence of disasters, beforehand assessment and investigation can be made, and put forward the corresponding treatment measures. For landslides and debris flow problems induced by particular topographical liquefaction, at first, we must solve how to distinguish liquefaction 
possibility and liquefaction degree of liquefied soil layer, because the existing theory and method is still can't solve this problem, then must predict the size of the liquefied landslide and debris flow and the hazard. We can solve these problems by the following process

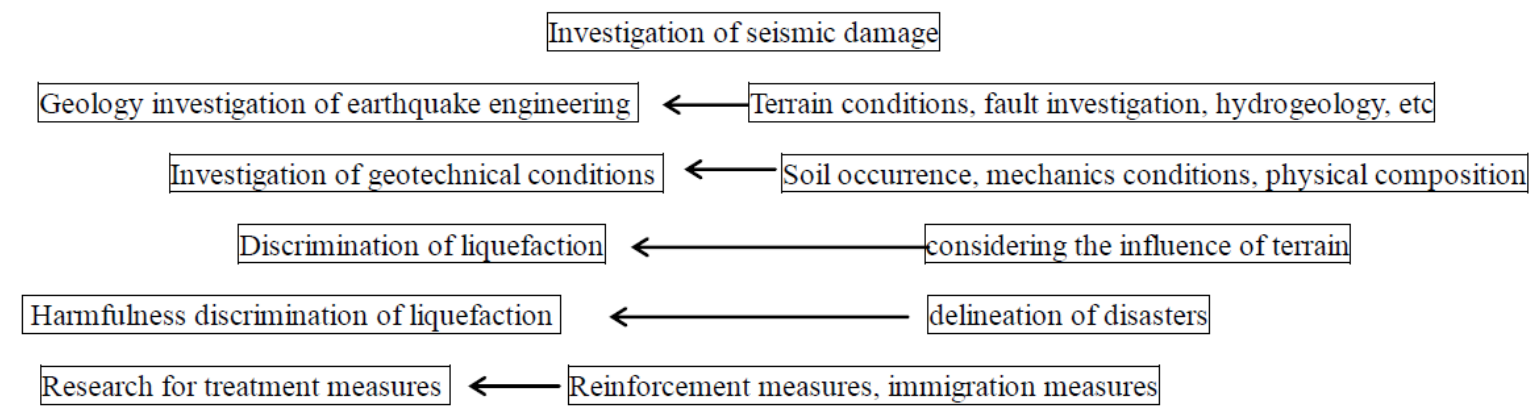

Fig. 14 A Process of Treatment and Defend the Slip and Debris by Seismic Liquefaction

\section{Conclusion}

Summing up the form of landslide and debris flow induced by the liquefaction from earthquake damage, through contrast prediction of the liquefied soil occurrence and analysis of liquefied happen and induced disasters, we can see that the causal relationship between terrain conditions, sandy soil layer occurrence and ground movement and deformation induced by liquefaction is obvious, it will provide scientific reference material for the prevention and control of the earthquake damage, and it will also give the simplified movement rules and equation of sliding body, and then provide reference to further study on the mechanism of the landslide and debris flow induced by liquefaction.

\section{Acknowledgement}

This work is supported by National Natural Science foundation of China (N0: 51178035).

\section{References}

[1]Chen Wenhua, Slipping disaster induced by seismic liquefaction [J], Journal of Natural Disasters, 2001,Vol10(4).

[2]Chinese investigation group for Japanese earthquake, The investigation report of the earthquake damage in Great Hanshin earthquake [M], Seismological Press, Beijing, 1995.

[3]Liu huixian, The Tangshan earthquake [M], Seismological Press, Beijing, 1995.

[4]Hamada M., Permanent deformation of ground and damages due to liquefaction[C]. 9th WCEE.

[5]Chen Wenhua, Monitoring rock slope slipping in three gorge and application of rock acoustic emission techniques [J], Journal of Natural Disasters, 1999,Vol8. 